\title{
Unilateral endoscopic forehead lift in facial palsy patient
}

\author{
II Gyu Kang, MD (iD \\ ENT Over Flower Clinic, Incheon, Rep. of Korea
}

\begin{abstract}
A 72-year-old man visited our clinic for correction of asymmetrical brow positioning and sagging of the left upper eyelid. The patient had had a left facial palsy for 16 years resulting in a left facial droop, which was especially noticeable in the left eyebrow. As the patient's facial palsy was unilateral, a unilateral forehead lift and internal fixation using 2-0 PDS were performed, which were appropriate than a bilateral endoscopic forehead lift. This case study aimed to examine how effective unilateral endoscopic forehead lift was for correcting the asymmetric eyebrows for a facial palsy patient.
\end{abstract}

Keywords: asymmetrical brow; facial droop; facial palsy; forehead; lift

\section{Introduction}

Facial nerve palsy, otherwise known as 'Bell palsy', has an incidence of 10 to 40 per 100,000 people and currently has no known cause [1]. Approximately 99\% of facial palsy is unilateral, resulting in noticeable asymmetry of the eyebrows [2]. To correct this issue, an endoscopic forehead lift is commonly used, as this technique allows the eyebrows to be raised as well as for lateral canthal hooding to be corrected. However, few reports have examined the effects of endoscopic forehead lifts for facial palsy; in particular, reports of unilateral endoscopic forehead lifts in facial paralysis patients are rare $[3,4]$. The purpose of this case was to examine the efficacy of unilateral endoscopic forehead lifts for correcting the asymmetric eyebrows in a facial palsy patient.

\section{Case report}

A 72-year-old man visited our clinic for the correction of asymmetrical brow positioning resulting from left facial palsy.
The patient had no history of any other disease. The patient's right side brow position was higher than left side brow (Fig. 1). Unilateral left side endoscopic forehead lift was planned to correct the patient's problems. An approximately $2 \mathrm{~cm}$-sized midline incision was made just behind the hairline, and an additional forehead incision was made $4 \mathrm{~cm}$ from the midline incision. A third temporal incision was also made for dissection of

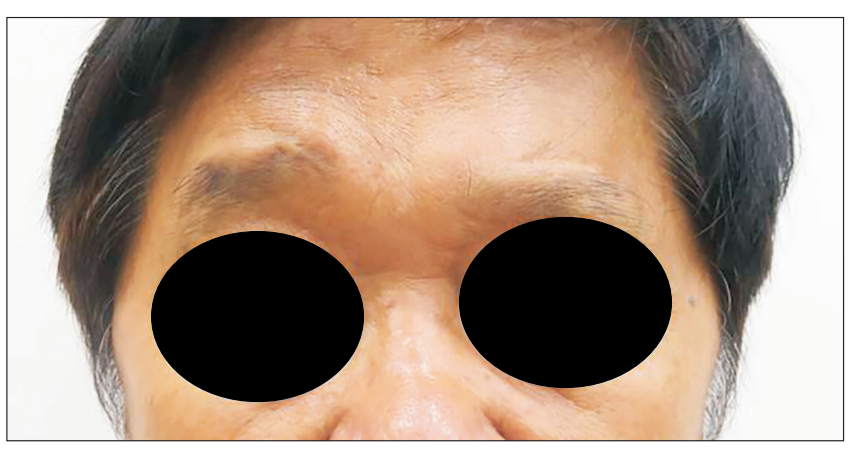

Fig. 1. Due to the left facial palsy, the left eyebrow is sagging compared to the right eyebrow. 


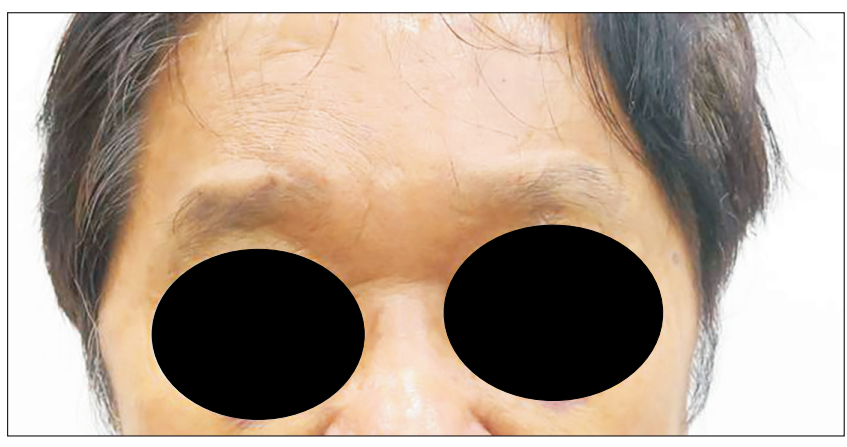

Fig. 2. Three months after unilateral endoscopic forehead lift, the left eyebrow was well raised.

the temporal area. Dissection was performed in a subperiosteal plane in the frontal area, and in a supra-deep temporalis fascial plane in the temporal area. During frontal dissection, the corrugator supercilli and depressor supercilli muscle were resected under endoscopy to facilitate elevation of the forehead flap, and the orbital ligament and lateral canthal raphe were released to facilitate elevation of the lateral brow. After dissection, the frontal flap was fixed to the bone using 2-0 PDS suture material via the bone bridge technique using a $1.2 \mathrm{~mm}$ diamond drill, and the inferior temporal flap was fixed to the deep temporalis fascia. Three months after operation, the unilateral endoscopic forehead lift has successfully corrected the patient's asymmetrical brow and lateral eyebrow sagging (Fig. 2). In addition, each patient consented to its publication.

\section{Discussion}

Peripheral paralysis of the facial nerve or its frontal branch may cause brow ptosis and eyelid deformities [3]. Endoscopic forehead lifts can also provide eyebrow lift, and thus can be applied for corrections to facial palsy. The asymmetry of eyebrow and eyelid are quite noticeable in facial palsy patients, and this technique is one method that can be used to improve this asymmetry. However, few articles have reported the use of endoscopic forehead lift in correcting this kind of problem in facial palsy patients $[3,4]$. Through this study, unilateral endoscopic forehead lift using 2-0 PDS was found to be successful in recreating symmetrical eyebrows in a facial palsy patient. Use of an endotine forehead device via an endoscopic approach also helped to recreate a symmetrical upper third of the face $[5,6]$. The unilateral endoscopic forehead lift has the advantage of short surgical time and quick recovery compared to the bilateral endoscopic forehead lift, and is thus a preferable technique for corrections of this type in facial palsy patients.

\section{Conflicts of interest}

The author has nothing to disclose.

\section{References}

1. Holland NJ, Weiner GM. Recent developments in Bell's palsy. BMJ 2004;329:553-7.

2. Williamson IG, Whelan TR. The clinical problem of Bell's palsy: is treatment with steroids effective? Br J Gen Pract 1996;46:743-7.

3. Holtmann L, Büchsenschütz K, Eckstein A, Schlüter A, Lang $S$, Mattheis S. [Endoscopic browlift via endotine forehead device in patients with facial palsy]. Laryngorhinootologie 2017;96:691-7. German.

4. Moody FP, Losken A, Bostwick J 3rd, Trinei FA, Eaves FF 3rd. Endoscopic frontal branch neurectomy, corrugator myectomy, and brow lift for forehead asymmetry after facial nerve palsy. Plast Reconstr Surg 2001;108:218-23.

5. Chowdhury S, Malhotra R, Smith R, Arnstein P. Patient and surgeon experience with the endotine forehead device for brow and forehead lift. Ophthalmic Plast Reconstr Surg 2007;23:358-62.

6. Pascali M, Gualdi A, Bottini DJ, Botti C, Botti G, Cervelli V. An original application of the Endotine Ribbon device for brow lift. Plast Reconstr Surg 2009;124:1652-61. 